\title{
Cloud-to-ground lightning over Mexico and adjacent oceanic regions: a preliminary climatology using the WWLLN dataset
}

\author{
B. Kucieńska ${ }^{1}$, G. B. Raga ${ }^{1}$, and O. Rodríguez ${ }^{2}$ \\ ${ }^{1}$ Centro de Ciencias de la Atmósfera, Universidad Nacional Autónoma de México, México \\ ${ }^{2}$ Instituto Mexicano de Tecnología del Agua, Jiutepec, Morelos, México
}

Received: 17 May 2010 - Revised: 28 October 2010 - Accepted: 29 October 2010 - Published: 9 November 2010

\begin{abstract}
This work constitutes the first climatological study of lightning over Mexico and adjacent oceanic areas for the period 2005-2009. Spatial and temporal distributions of cloud to ground lightning are presented and the processes that contribute to the lightning variability are analysed.

The data are retrieved from the World Wide Lightning Location Network (WWLLN) dataset. The current WWLL network includes 40 stations which cover much of the globe and detect very low frequency radiation ("spherics") associated with lightning.

The spatial distribution of the average yearly lightning over the continental region of Mexico shows the influence of orographic forcing in producing convective clouds with high lightning activity. However, a very high number of strikes is also observed in the States of Tabasco and Campeche, which are low-lying areas. This maximum is related to the climatological maximum of precipitation for the country and it may be associated with a region of persistent low-level convergence and convection in the southern portion of the Gulf of Mexico.
\end{abstract}

The maps of correlation between rainfall and lightning provide insight into the microphysical processes occurring within the clouds. The maritime clouds close to the coastline exhibit similar properties to continental clouds as they produce very high lightning activity.

The seasonal cycle of lightning registered by WWLLN is consistent with the LIS/OTD dataset for the selected regions. In terms of the annual distribution of cloud-to-ground strikes, July, August and September exhibit the highest number of strikes over continental Mexico. The diurnal cycle indicates that the maximum number of strikes over the continent is observed between 6 and 9 p.m. LT.

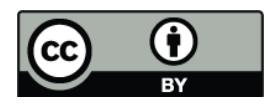

Correspondence to: G. B. Raga

(raga@ servidor.unam.mx)
The surrounding oceanic regions were subdivided into four distinct sectors: Gulf of Mexico, Caribbean, Subtropical Pacific and Tropical Pacific. The Gulf of Mexico has the broadest seasonal distribution, since during winter lightning associated with mid-latitude systems also affects the region. The diurnal distribution of lightning for the Gulf of Mexico exhibits the highest number of strokes at 9 a.m. The Caribbean seasonal distribution is slightly biased towards early fall, with a clear maximum observed during October. The diurnal distribution of lightning over the Caribbean is quite uniform with a slight increase near midnight. The Subtropical Pacific has the narrowest seasonal distribution, associated with the convection observed during the "North American Monsoon", with the maximum number of strikes during August and September. In contrast, the Tropical Pacific has a broader seasonal cycle, associated with convection in the Inter-Tropical Convergence Zone (ITCZ), starting in May and lasting till October. In both adjacent Pacific regions, the strikes present a maximum in the early morning, the time of the highest frequency of land breeze.

Keywords. Meteorology and atmospheric dynamics (Atmospheric electricity; Climatology; Lightning)

\section{Introduction}

Convective clouds of large vertical extent very often develop a strong electric field through interactions between different types of hydrometeors. The charge is exchanged during the interaction of actively growing graupel (in the presence of supercooled water) and cloud ice crystals (Saunders, 2008). For convective updrafts, the basic charge structure is comprised of four charge regions: relatively weak positive charge in the lowest part of the cloud, main negative and upper positive charge regions historically described as the "main dipole", and a shallow uppermost region with a

Published by Copernicus Publications on behalf of the European Geosciences Union. 


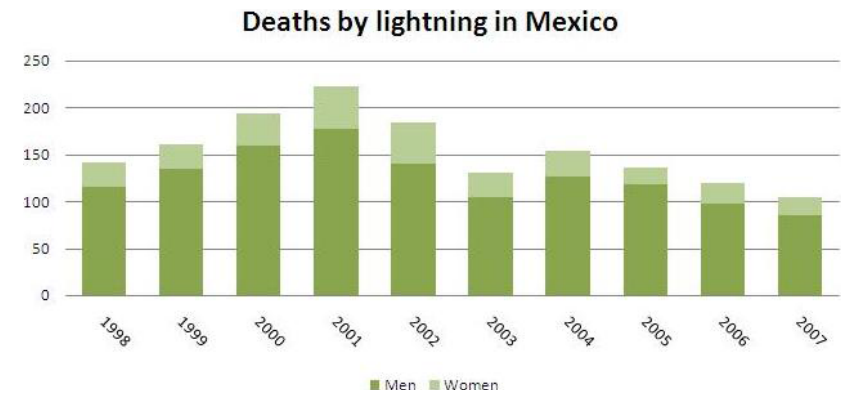

Fig. 1. Deaths by lightning occurred in Mexico between 1998 and 2007.

negative charge. Outside the updrafts, but still within a convective region of the storm, there are at least six charge regions (Stolzenburg et al., 2009).

Most of the lightning occurs within the cloud (Mackerras et al., 1998). A fraction of lightning can also occur between different clouds and about a third of the total lightning flashes strike the ground (Boccippio et al., 2001). These are the ones that constitute a hazard to the population. During the 10-year period, from 1998 to 2007, an average of 155 people died per year in Mexico from lightning strokes (as shown in Fig. 1), with men accounting for $81 \%$ of the victims. Most of those casualties occur during July, August and September when people are working in the fields (online database DGIS, http://www.sinais.salud.gob.mx). Moreover, lightning is the most frequent cause of natural forest fires, which pose threats to nearby populations and ecosystems, and can provoke major disruption in the distribution of electrical power, when high voltage towers are struck by it. Most of the electrical power in Mexico is obtained from hydroelectric plants in the Southern states of Oaxaca and Chiapas, where most of the precipitation falls. This electricity is then transported through high voltage lines in towers towards the regions where the demand is highest and most of the population lives. The maps presented in this study provide information on the regions that would be most vulnerable to tower damage due to lightning strokes. The data analysed will be incorporated into a national natural hazard atlas to highlight those regions.

The lightning sensor mounted on the TRMM satellite, can only detect lightning during about $90 \mathrm{~s}$ over each individual pixel across the swath, which does not allow the study of the evolution within convective systems but only gives a snapshot of the convective activity (Cecil et al., 2005). It is, however, very useful to determine climatological mean conditions and the data are freely available from websites.

In this paper we use the dataset derived from the World Wide Lightning Location Network (WWLLN), which is currently the only real-time network that covers the entire globe (Rodger et al., 2005). The stations of this network are primarily located at academic institutions distributed around the world. The network is managed at the University of Wash- ington. The study attempts to produce the first preliminary climatology of the spatial and temporal distribution of cloud to ground lightning over continental Mexico and surrounding oceanic areas. This information can be used to derive maps of lightning probabilities, which can allow authorities to plan ahead, for example the deployment of high voltage distribution lines. For civil defence planning purposes it is important to know at what time the lightning is more likely to occur. The fine scale diurnal pattern of convection close to the land is of great interest to the population that lives in coastal regions and works offshore in the fishery and the oil exploration industries.

\section{Database}

The World Wide Lightning Location Network (http://www. wwlln.net) provides real time lightning locations around the globe by measuring the very low frequency radiation (VLF, 3-30 kHz, also called "atmospherics" or simply "spherics") produced during a lightning bolt (Rodger et al., 2004). The location algorithm takes into account the events recorded by at least 5 receiving stations around the world. Each receiving station in the network is similar and consists of an antenna to measure the VLF electric field, a global positioning system antenna to accurately time each event, an amplifier and a computer connected to the Internet. When a spherics signal reaches a station, the information of the time of group arrival (TOGA) is then sent to the central processing computer. The algorithm then combines the information from at least 5 stations to determine the latitude and longitude of the lightning strike (Dowden et al., 2002). The accuracy and detection efficiency of the network have been estimated for a few regions, by comparing with regional surface networks (Lay et al., 2004, 2007; Jacobson et al., 2006; Ramachandran et al., 2007). The accuracy was found to be location-dependent and vary between 4 and $14 \mathrm{~km}$. Recently, the location accuracy of WWLLN was shown to have a northward and westward bias, with average location errors of $4.03 \mathrm{~km}$ in the northsouth and $4.98 \mathrm{~km}$ in the east-west directions (Abarca et al., 2010).

The World Wide Lightning Location Network is under the process of constant development and its detection efficiency increases every year. Abarca et al. (2010) evaluated the WWLLN by using the National Lightning Detection Network as ground truth, and they found that the overall detection efficiency of cloud-to-ground flashes increased from $3.88 \%$ in $2006-2007$ to $10.30 \%$ in $2008-2009$. They also found that the cloud-to-ground detection efficiency is strongly dependent on peak current and polarity, attaining values larger than $10 \%$ (35\%) for currents stronger than $\pm 35 \mathrm{kA}(-130 \mathrm{kA})$ and smaller than $2 \%$ for currents between 0 and $-10 \mathrm{kA}$.

The study also presents results from the Lightning Imaging Sensor (LIS), Optical Transient Detector (OTD) and the 
3B42 TRMM precipitation product. LIS is an instrument on board the Tropical Rainfall Measuring Mission (TRMM) Observatory used to detect the distribution and variability of total lightning (Kummerow and Barnes, 1998). The Optical Transient Detector (OTD) was developed as an inhouse project at NASA's Marshall Space Flight Center in Huntsville, Alabama. It was a scientific payload on the MicroLab-1 satellite that was launched in April 1995 (Christian et al., 2003) and recorded the occurrence and worldwide distribution of lightning until April 2005. The TRMM 3B42 product (Kummerow et al., 2000) uses an optimal combination of other products and precipitation estimates to produce merged high quality infrared precipitation. The gridded estimates are on a three-hour temporal resolution and a 0.25 degree by 0.25 degree spatial resolution in a global belt extending from 50 degrees South to 50 degrees North latitude.

\section{Results}

In this study we analyse the lightning activity averaged over the five year period: 2005-2009. The characteristics of convective activity over land and ocean vary significantly, both in the forcing mechanisms and the concentrations and sizes of cloud condensation and ice nuclei that are crucial for cloud droplet and ice crystal formation. Therefore, the region of study was divided into continental Mexico and 4 oceanic sectors: Gulf of Mexico, Caribbean, Subtropical Pacific and Tropical Pacific. Figure 2 shows a map with the limits of each sector clearly indicated.

\subsection{Average spatial distribution of lightning}

Figure 3 presents the spatial distribution of an average density of lightning strokes for each month of the year. The lightning density is expressed as a number of strokes per month per $\mathrm{km}^{2}$. The maps are created on a grid with horizontal and vertical resolution of 0.25 degree, which is more than 5 times greater than the location accuracy of WWLLN evaluated by Abarca et al. (2010).

The months of November till March roughly correspond to the dry season in Mexico and therefore very little activity is seen over the continental Mexico for this period. However, the lightning associated with the mid-latitude systems is noticeable in the northern part of the Gulf of Mexico during winter. Lightning activity over the continent becomes stronger in April, particularly in the region corresponding to the Sierra Madre Oriental (the mountainous range running roughly parallel to the coast of the Gulf of Mexico) and also in the region of western Chiapas in southern Mexico, at the Tropical Pacific coast.

By May lightning activity becomes more widespread over continental Mexico, with only a few regions exhibiting relatively small activity (e.g. the Yucatan peninsula, and northwest continental Mexico). There is a high concentration of

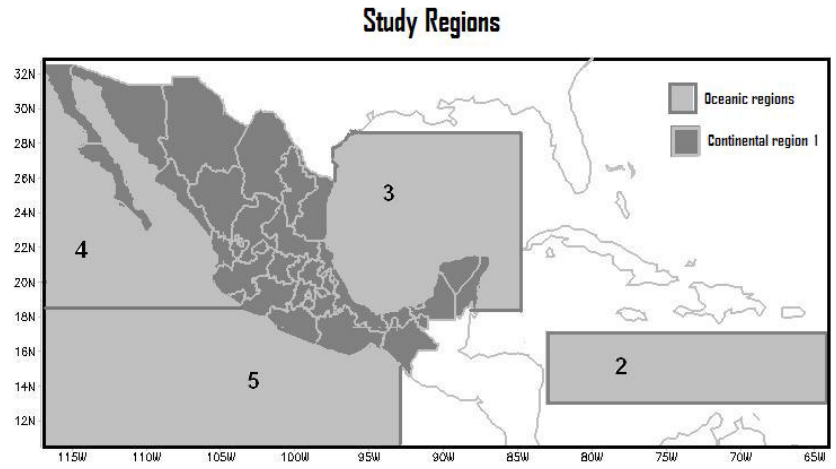

Fig. 2. Map delimiting the 5 different sub-regions considered: (1) continental Mexico, (2) Caribbean, (3) Gulf of Mexico, (4) SubTropical Pacific and (5) Tropical Pacific.

lightning strokes over the coastal oceanic zone of the Tropical Pacific, as the Inter-tropical Convergence Zone becomes established in this region and the effects of thermal convection become stronger. From May to July the signal of high lightning activity moves northward along the Pacific coast of Mexico, finally reaching the northernmost regions of Mexico and the border with Arizona. This area of high lightning density is related to the development of convective clouds intensified by orographic forcing by the chain of mountains (Sierra Madre Occidental) which extends throughout the whole Pacific coast of Mexico.

During summer, a very high lightning activity is also observed in the states of Veracruz and Tabasco, and it spreads along the southern coast of the Gulf of Mexico from June to September, reaching the states of Campeche, Yucatan and Quintana Roo. Summer months correspond to the season of tropical storms and hurricanes over the Gulf of Mexico, with the maximum activity registered in September (Jáuregui, 2003). In October the number of strokes over this area decreases. The persistent region of high lightning density over the Southern Gulf of Mexico (from June to October) is correlated with the climatological maximum of annual precipitation, shown by the Mexican Weather Service (http://smn.cna.gob.mx).

September and October show a decrease in the lightning activity in Northwest Mexico as the autumn progresses and convection becomes weaker. This spatial and temporal distribution of lightning strokes is clearly related to the socalled "Monsoon of North America", a mesoscale circulation linked to the sea-land contrast, which results in convection and precipitation over land concentrated in the months of July till September.

\subsection{Correlation between lightning and rainfall}

The maps presented in Fig. 4 show spatial and temporal variations of the correlation coefficient between precipitation and 

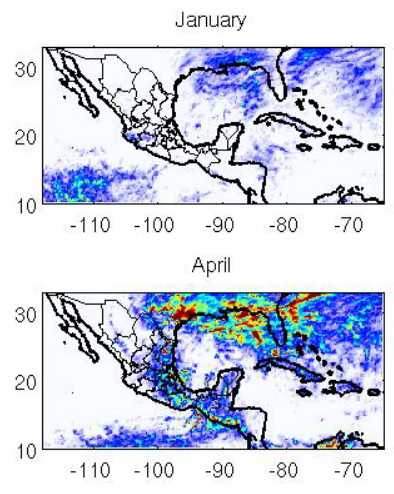

July
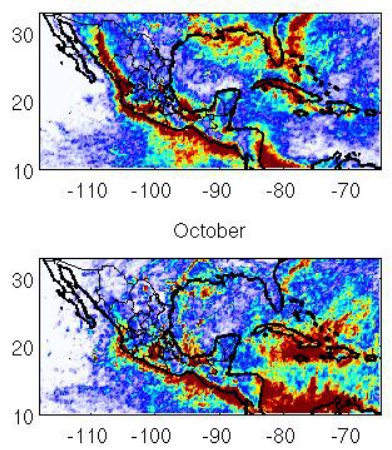

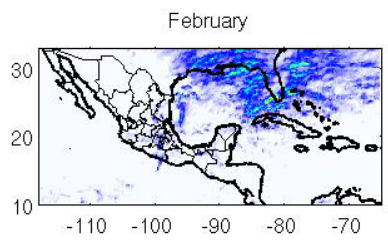

May
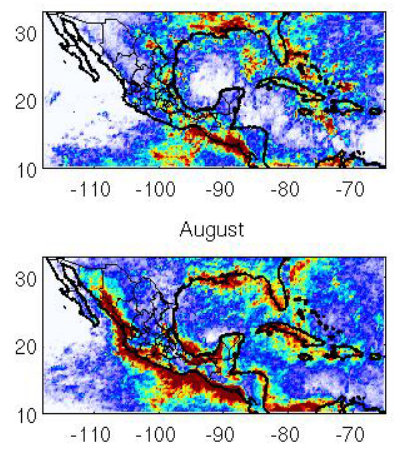

November

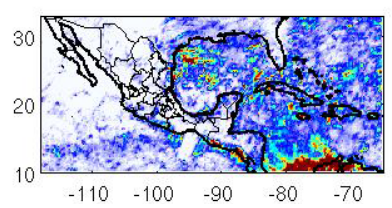

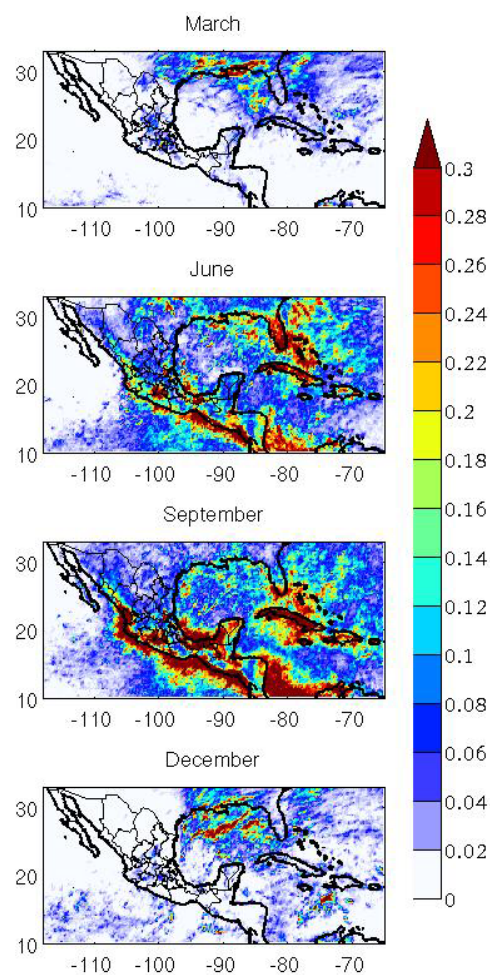

Fig. 3. Spatial distribution of cloud-to-ground strokes per month per $\mathrm{km}^{2}$, averaged over the five-year period (2005-2009).

lightning. The correlation coefficient $r_{x y}$ is defined at each point of the grid as:

$$
r_{x y}=\frac{\left(x_{i}-X\right)\left(y_{i}-Y\right)}{\sqrt{\frac{1}{N} \sum_{i}^{N}\left(x_{i}-X\right)^{2}} \sqrt{\frac{1}{N} \sum_{i}^{N}\left(y_{i}-Y\right)^{2}}}
$$

where $x_{i}$ and $y_{i}$ are precipitation and lightning densities at a given point $i$ of the grid, and $X$ and $Y$ are spatial monthly averages of precipitation and lightning calculated over $N$ points of the grid that covers the region under study. The grid has zonal and meridional resolution of $0.25^{\circ}$, so $x_{i}$ and $y_{i}$ represent local averages for the individual grid cells. The precipitation values were retrieved from the 3B42 TRMM product and averaged over the same period as the WWLLN lightning dataset (2005-2009).

From December to April there is a strong correlation between rainfall and lightning over the northern coast of the Gulf of Mexico. Winter precipitation over this area is a result of cold fronts that cause a rapid decrease in temperature and development of cumulonimbus clouds with lightning activity. However, in May the correlation over this area becomes much smaller. The rainfall in May and June (not shown) over the northern coast of the Gulf of Mexico decreases as compared to winter months but flash density increases (see Fig. 3). The explanation for this phenomenon can be related to the microphysical cloud properties and vertical hydrometeor profiles that change throughout the year and differ for clouds formed over land and ocean. Kucieńska and Raga (2010) analyzed vertical profiles of hydrometeors in precipitating clouds over the Pacific coast of Southern Mexico, retrieved from TRMM data, and found that from April to May there is a strong increase in the amount of precipitating ice, especially over the land. Summer precipitation was found to be almost entirely the result of melted ice, whereas during winter there was a large contribution from warm precipitation to total rainfall. Montero et al. (2010) arrived to similar conclusions for clouds over central Mexico, where Mexico City is located. Moreover, Peterson et al. (2005) studied the relation between ice content and lightning registered by TRMM sensors and found that the amount of precipitating ice is highly correlated to lightning flash density. This correlation is so robust that they suggested that the lightning data can be used to retrieve the ice content. The spring and summer cumulonimbus clouds form over the Gulf of Mexico by convection resulting from wind convergence due to the intensification of Azores-Bermuda high (Romero-Centeno et al., 2007). Therefore the updrafts during spring and summer are expected to be stronger than those which result from the passage of cold fronts during winter at these low latitudes; stronger updrafts usually lead to higher ice amounts within clouds. The increase in the amount of ice from winter to summer is a likely explanation for the increase of lightning over the northern Gulf of Mexico (Fig. 3) and the decrease in the correlation between lightning and rainfall (Fig. 4), however 

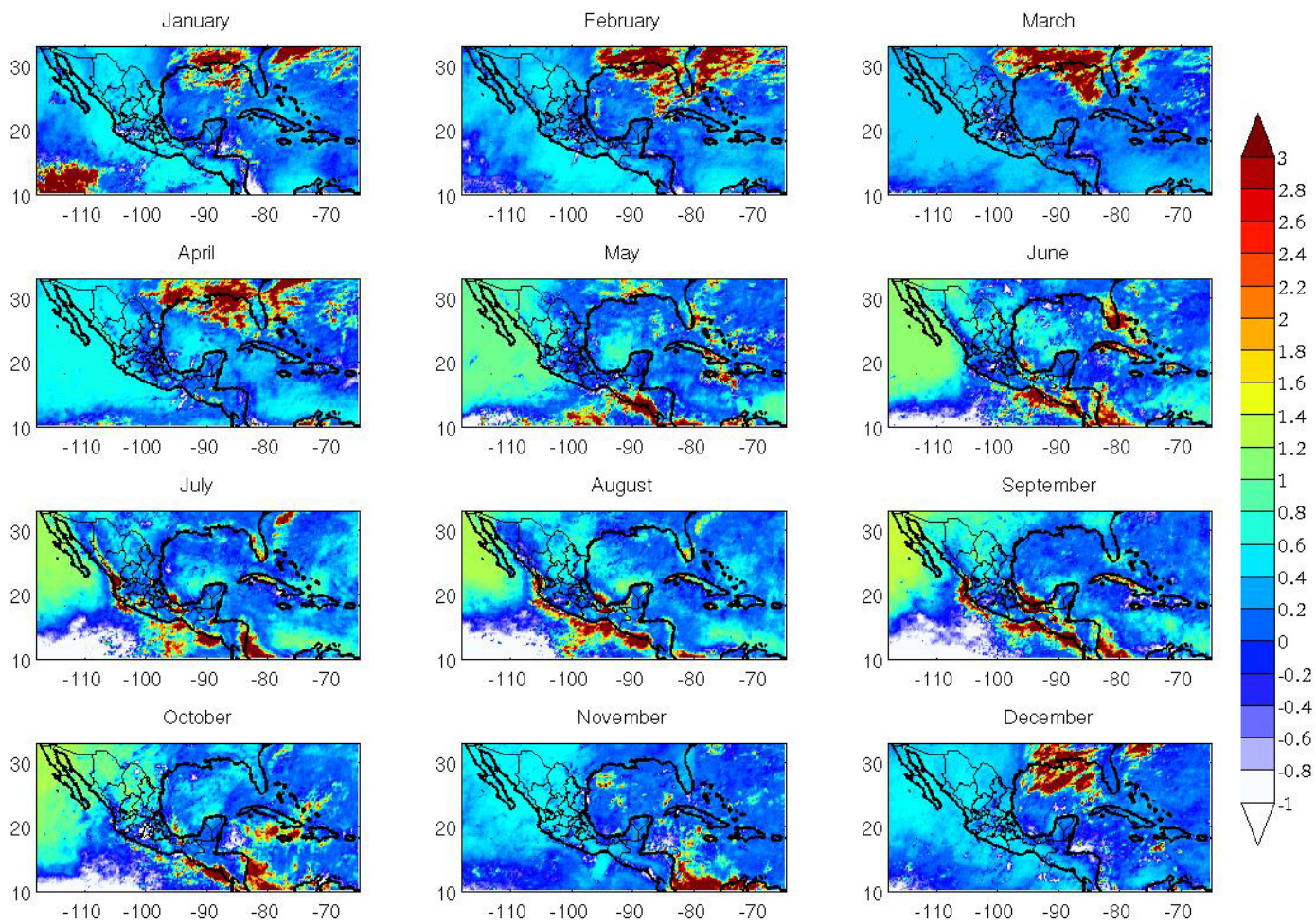

Fig. 4. Annual distribution of the spatial correlation coefficient between rainfall and lightning. The correlation coefficient is defined in the Eq. (1).

the analysis of the vertical profiles of hydrometeors over this region is necessary to confirm this hypothesis. Such an analysis is beyond the scope of this paper which constitutes a climatological study and it will be done in the companion paper that focuses on the processes.

During the whole summer, the correlation between lightning and precipitation over the Gulf the Mexico is relatively low, with the exception of the coastal regions of the Mexican states of Tabasco and southern Veracruz. In these regions both lightning density and rainfall have high values due to strong updrafts caused by wind convergence (RomeroCenteno et al., 2007). A significant lightning activity is also observed over the northern coast of the Gulf of Mexico (Fig. 3), especially in July and August, but rainfall over this area is much smaller than that over Tabasco and therefore the correlation between them is not as high.

From June to September, there is a high correlation between rainfall and lightning at the Pacific coast of Mexico. As already mentioned, the amount of precipitating ice is very high within the summer clouds over this region (Kucieńska and Raga, 2010) and so is lightning density. The mountain ranges located very close to the coastline enhance the precipitation over the coastal region and inhibit its inland propagation. The mountains of northern Mexico are located further from the Pacific coast than in the south, and therefore rain and lightning activity can propagate further inland (Fig. 3).
This topographic influence can be also observed in the correlation maps between lightning and rainfall, especially in July (Fig. 4).

From May to October an anti-correlation can be observed over the Tropical Pacific away from the coastline (white areas in the Fig. 4). This anti-correlation indicates the region where rainfall is very high (not shown) and lightning density is low (Fig. 3). High precipitation results from strong wind convergence over this area (Romero-Centeno et al., 2007) and low lightning activity is a result of microphysical properties of cloud condensation nuclei and droplets that develop on them, as well as the evolution of ice crystals and graupel. The clouds which form over the oceanic areas close to the coastline have similar microphysical properties to continental clouds. Baumgardner et al. (2006) studied the evolution of anthropogenic aerosols in the coastal town of Salina Cruz and found that the maximum concentrations of condensation nuclei occur during land breeze periods. Moreover, $\mathrm{Ku}-$ cieńska and Raga (2010) showed that the maximum rainfall and lightning activity over the seaside coastal region close to the town of Salina Cruz also occur at the time of the highest land breeze frequency (early morning). It is well known that droplet spectra in continental clouds are dominated by small and numerous droplets (e.g. Hudson and Yum, 2001). This kind of spectrum causes a rapid ascent of air parcel due to a great release of latent heat (Kucieńska et al., 2010). It 

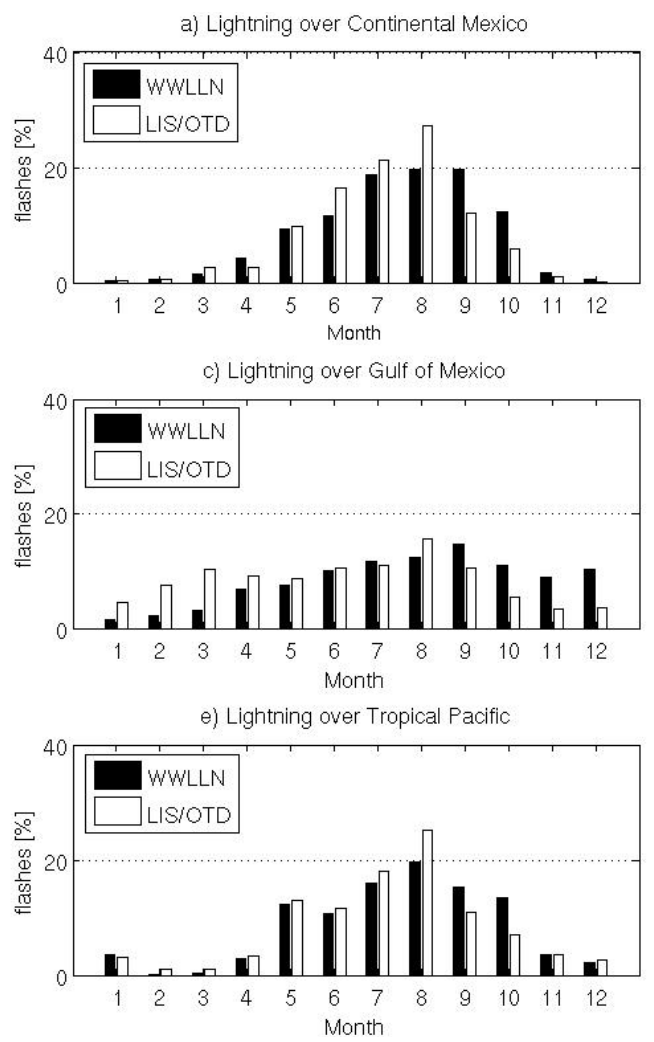
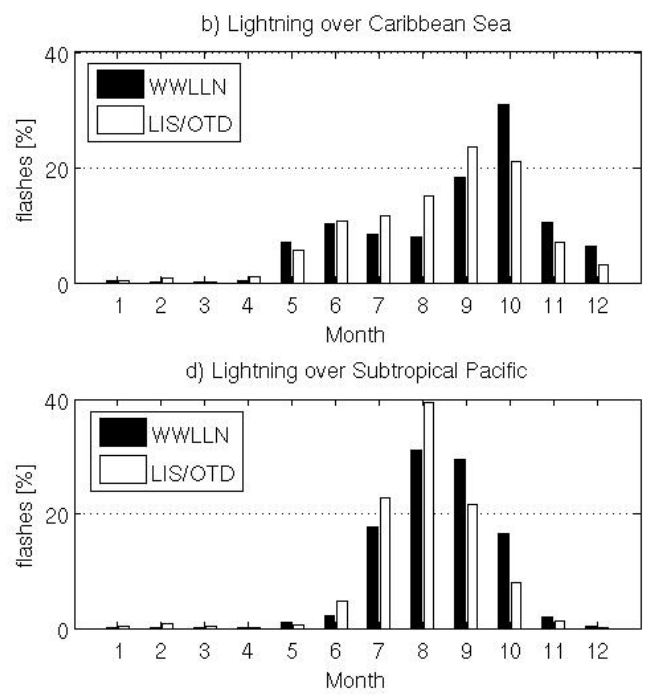

Fig. 5. Average seasonal cycle of lightning strokes in percentage for (a) continental Mexico, (b) Caribbean Sea, (c) Gulf of Mexico, (d) Subtropical Pacific and (e) Tropical Pacific. Bars in black represent the 5-year average obtained from the WWLLN dataset during the period 2005-2009. Bars in white indicate the total lightning recorded by OTD and LIS from 1995 to 2005.

is very difficult for a spectrum composed of small and numerous droplets to generate precipitation through collisions and coalescence (warm precipitation). Instead of precipitating, the droplets are carried by the updrafts above the $0{ }^{\circ} \mathrm{C}$ isotherm and participate in mixed-phase processes, which are also involved in charge separation within a cloud (Avila et al., 1999). Cloud droplets over oceanic zones away from the coast form on cloud condensation nuclei with larger sizes and smaller concentrations (Twomey and Wojciechowski, 1969). This kind of spectrum favours the fast growth of droplets that initiate the process of collision-coalescence; therefore the formation of raindrops below the $0^{\circ} \mathrm{C}$ isotherm is more common in maritime clouds than in continental clouds. If most of the precipitation is a result of warm rain processes in clouds of moderate vertical extent (5-6 km in height), then very little electrical activity would be observed. Figure 4 illustrates very well the different nature of clouds that form close to the coastline and those away from the coast. Summer clouds over the Tropical Pacific region away from the Mexican coastline (white areas in the Fig. 4) have low lightning activity in spite of the very high rainfall, while those that form close to the coastline (red areas in the Fig. 4) produce high rainfall and high lightning densities. This result is consistent with the conclusions of Takayabu (2006) who found that rain-yields per flash in the tropics, calculated from the TRMM Precipitation Radar (PR) and LIS data, are much larger over oceans than over continents and this difference is due to the reduced lightning activity over oceans. Weaker updrafts over the oceans can make cloud lifetime insufficient for the development of the electrical field close to the breakdown point. Moreover, smaller amounts of ice that result from weaker updrafts imply lower efficiency of the processes of charge separation.

Note that in January there is a high correlation between lightning and rainfall over the same area where the correlation is negative in summer, and it is difficult to explain. Winter rainfall over this area $\left(110^{\circ} \mathrm{W}-120^{\circ} \mathrm{W}, 10^{\circ} \mathrm{N}-15^{\circ} \mathrm{N}\right)$ is much smaller than during summer but lightning activity registered by WWLLN is greatest in January. Moreover, the number of flashes in January over this part of the ocean is greater than in December and February (Fig. 3) and so is rainfall (not shown). Also the LIS dataset, discussed in the Sect. 3.3, shows more flashes over this region of the Tropical Pacific in January than in December or February (Fig. 5e). The increase in rainfall and lightning activity indicates the existence of stronger updrafts which would lead to higher ice amounts; however the mechanism responsible for the strengthening of the updrafts over this area in January is unknown. 
Table 1. Average number of flashes per $\mathrm{km}^{2}$ per year detected by the WWLLN for each region considered in this study.

\begin{tabular}{lccccc}
\hline Region & Continental Mexico & Caribbean Sea & Gulf of Mexico & Subtropical Pacific & Tropical Pacific \\
\hline Flashes $/ \mathrm{km}^{2} /$ year & 0.68 & 0.56 & 0.78 & 0.13 & 0.55 \\
\hline
\end{tabular}

The above results show that the combined information of lightning and precipitation provides insight into the type of microphysical processes that occur within the clouds over different regions analysed in this study.

\subsection{Average seasonal cycle per region}

Figure 5 presents the seasonal variability of lightning for the five regions considered in this study. The WWLLN data are here compared with the lightning climatology registered by Lightning Imaging Sensor (LIS) and the Optical Transient Detector (OTD). The LIS/OTD data shown in the Fig. 5 are retrieved from the High Resolution Monthly Climatology (HRMC) product which includes the climatologies from the 5-year OTD (4/95-3/00) and 8-year LIS (1/98-12/05) missions, as well as a combined OTD/LIS climatology and supporting base data (flash counts and viewing times). HRMC is a 0.5 degree by 0.5 degree gridded monthly average of total lightning bulk production, expressed as a flash density (flashes $/ \mathrm{km}^{2} /$ day) and centred on the 15 th day of each month.

The monthly variability in the Fig. 5 is expressed as a percentage of the monthly number of flashes with respect to the annual number of flashes for a given region. The absolute number of flashes per $\mathrm{km}^{2}$ per year, averaged over 5 years, is given for each region in Table 1.

Due to the low detection efficiency of the WWLLN, the difference between absolute values of flashes detected by WWLLN and LIS/OTD is about one order of magnitude. A similar difference was also observed, when lightning registered by the WWLLN was compared with the National Lightning Detection Network data (Abarca et al., 2010).

Even though the WWLLN data used in this study and the LIS/OTD HRMC product do not cover the same time period, it is remarkable that the relative monthly variability of lightning is very similar for both datasets. Both WWLLN and LIS/OTD data exhibit maximum lightning density in August over the Tropical Pacific and the Subtropical Pacific regions. Over the continent, the maxima detected by WWLLN occur in August and September and LIS/OTD maximum is clearly defined for August. Over the Gulf of Mexico, a maximum number of flashes was registered by LIS/OTD in August, while the WWLLN data indicate the maximum in September. In the case of the Caribbean Sea, LIS/OTD registered a maximum number of flashes in September, while the WWLLN highest lightning activity occurs in October. The discrepancies between both datasets can be caused by different time periods of WWLLN and LIS/OTD records and small num-

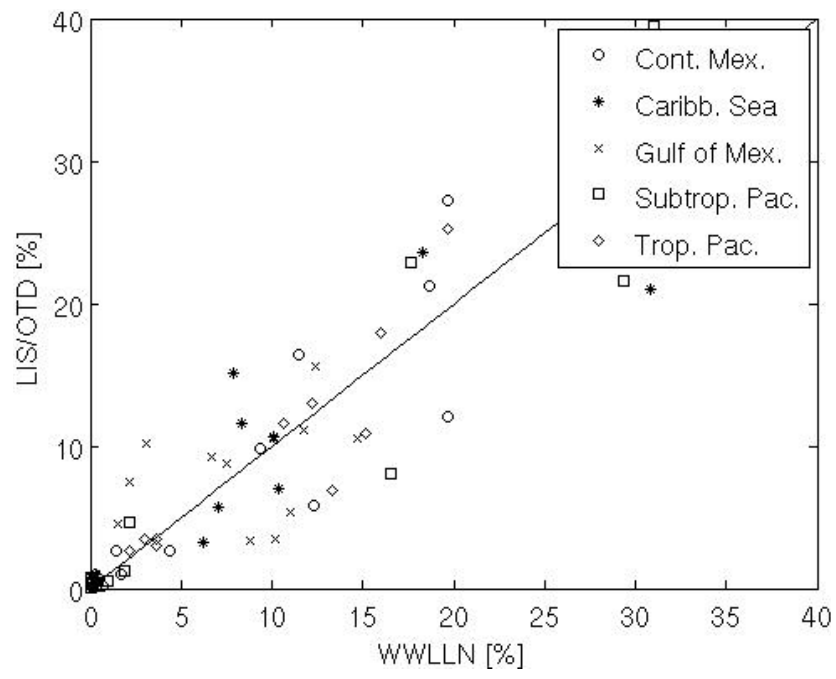

Fig. 6. Dispersion diagram between the monthly percentages of flashes registered by WWLLN and LIS/OTD sensors for each region.

ber of years of WWLLN data. The fact that the satellite sensors detect total lightning while WWLLN registers mainly cloud-to-ground lightning can also be important, as the ratio between cloud-to-ground strokes and total lightning can vary throughout the year. Taking into account the above differences, both datasets are very consistent when representing the seasonal cycle of lightning in terms of percentage. Figure 6 shows the dispersion between monthly percentages of flashes registered by WWLLN and LIS/OTD sensors, which is smaller than $10 \%$ for all the regions.

Lightning variability is clearly related to the type of convective activity that occurs in each region. The highest annual flash densities were registered over Gulf of Mexico and continental Mexico and the lowest flash activity occurs over Subtropical Pacific, as shown in the Table 1.

Over continental Mexico (Fig. 5a), 91\% of lightning strokes are registered by WWLLN between May and October, months that correspond to the rainy season. A broad maximum occurs in July, August and September, the three months exhibiting very similar number of flashes. There is a continuous decrease of flash density from September to January and an increase from January to August. The spatial variability of precipitation and lightning over continental Mexico is very high, as shown in the Figs. 3 and 4, but the seasonal cycle of the spatial average of lightning is consistent 
with the seasonal variability of rainfall averaged over the Mexican Republic.

Lighting activity over the Caribbean Sea (Fig. 5b) starts in May and ends in December, the period that corresponds to the rainy season for this area. Annual rainfall over the Caribbean exhibits a bimodal structure with two rainfall maxima (May-June and September-October) separated by what was termed a mid-summer drought, occurring in July and August (Gamble et al., 2008; Magaña et al., 1999). The seasonal cycle of lightning, showed in the Fig. 5b, is consistent with the cycle of rainfall: the early rainfall season mode occurs in June and the late rainfall season mode is clearly defined for October. There is a relative minimum in flash density in July and August.

The Gulf of Mexico (Fig. 5c) has the broadest and most uniform lightning distribution. Lightning activity is significant throughout all the year due to the presence of midlatitude systems during winter. From September to December the WWLLN lightning density is higher than that of LIS/OTD and the opposite situation occurs from January to May. In general, lightning activity over the Gulf of Mexico is only slightly lower during winter than that during summer, which can also be noted in the maps of spatial distribution of lightning (Fig. 3).

The Subtropical Pacific region (Fig. 5d) exhibits the narrowest seasonal distribution. Maximum lightning density was registered by WWLLN in August and September, and the flashes occurring from July to October represent $95 \%$ of the annual average. This high lightning activity during the summer months over the Subtropical Pacific is associated with strong convection observed during the "North American Monsoon".

Spatial averages of lightning over the Tropical Pacific presented in Fig. 5e include a coastal region with high lightning density (see Fig. 3) and the areas located away from the coast where the lightning activity is much weaker; therefore the main contribution to the lightning variability presented in this figure comes from the flashes registered close to the coastline. The Tropical Pacific presents significant lightning activity between May and October. The flash density decreases from May to June, increases from June to August and again decreases from August to October. Kucieńska and Raga (2010) analysed the monthly variability of precipitation and lightning over the Pacific coast of southern Mexico $\left(12^{\circ} \mathrm{N}-15^{\circ} \mathrm{N}, 93^{\circ} \mathrm{W}-101^{\circ} \mathrm{W}\right)$ and found that summer months with maximum precipitation (June and September) exhibited lower lightning density than the months corresponding to the so-called mid-summer drought (July and August). The seasonal cycle of lightning was the same as that in Fig. 5e, although the Tropical Pacific region analysed in the present paper is larger than that in the study of Kucieńska and Raga (2010). The hydrometeor profiles retrieved from the TRMM dataset for the area located close to the coastline did not show significant differences in the amounts of precipitating ice for the summer months (May to October) and the explanation for the observed discrepancy between rain and lightning seasonal cycles over the Tropical Pacific remains an open issue.

\subsection{Average diurnal cycle per region}

The diurnal cycle of lightning is in general consistent with that of convective rainfall (Tapia et al., 1998; Kucieńska and Raga, 2010). Kikuchi and Wang (2008) studied diurnal precipitation regimes in the global tropics with TRMM data and identified three tropical diurnal cycle regimes (oceanic, continental, and coastal) according to the amplitude, peak time, and phase propagation characteristics of the diurnal precipitation. They found that the oceanic regime is characterized by moderate amplitude and an early morning peak [06:00-09:00 Local Solar Time (LST)] and the continental regime has large amplitude and an afternoon peak (15:0018:00 LST). The coastal regime shows large amplitude and phase propagation, and is characterized by two subregimes, often concurring along the same land-sea boundary. The seaside coastal regime is characterized by an offshore phase propagation, with peaks occurring from late evening to noon of the next day (21:00-12:00 LST), whereas the landside coastal regime has landward phase propagation with peaks occurring from noon to evening (12:00-21:00 LST).

Lay et al. (2007) argued that the WWLLN local time variations of flash density, averaged over one year are consistent with satellite and regional ground-based studies, and can be used to study the land/ocean diurnal cycle of lightning. The diurnal cycle analysed in this paper is averaged over five years and the spatial averages are considered for the continental Mexico and the four adjacent oceanic regions.

The diurnal variation of lightning strokes to ground over continental Mexico is presented in the Fig. 7a. It exhibits maximum activity between 6 p.m. and 9 p.m. of local time and a minimum between 9 a.m. and midday. As shown in Fig. 3, there is a very high contribution from lightning over coastal areas to total number of flashes over continental Mexico and this contribution is reflected in the diurnal cycle of lightning averaged for the Mexican Republic, as the maximum occurs later than expected for the typical continental regime studied by Kikuchi and Wang (2008). The diurnal evolution of lightning over continental Mexico reflects variation in land heating by solar radiation together with sea-land and valley-mountain breeze cycles at the coastal areas.

The diurnal lightning patterns are very similar over the Subtropical and Tropical Pacific regions (Fig. 7d and e) with the minimum activity occurring between 3 p.m. and 6 p.m., and maximum activity between midnight and $9 \mathrm{a} . \mathrm{m}$. The diurnal evolution of precipitation and lightning over the Pacific coast of southern Mexico follows the land-sea breeze circulation measured by Baumgardner et al. (2006) in the coastal town of Salina Cruz: the maximum lightning and rainfall coincide with the maximum frequency of land breeze, observed at about 6 a.m. The diurnal cycles of lightning over both 

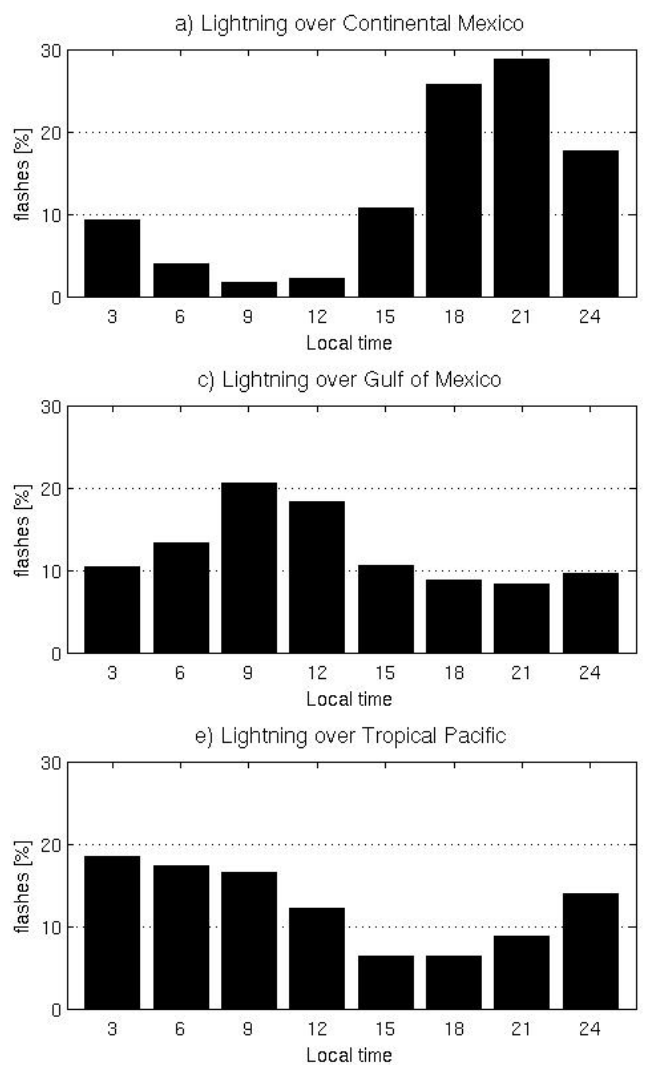
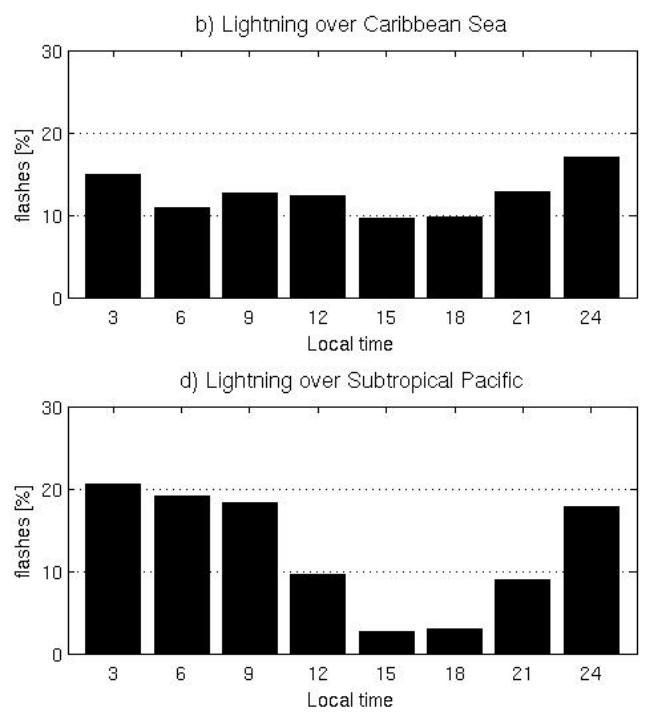

Fig. 7. Average diurnal cycle for the total number of cloud-to-ground strokes in percentage for (a) continental Mexico, (b) Caribbean Sea, (c) Gulf of Mexico, (d) Subtropical Pacific and e) Tropical Pacific. The three-hour lightning accumulates are centred at the hours indicated in the figure.

Pacific regions studied in this paper are also in agreement with the analysis of Kikuchi and Wang (2008) who found that maximum rainfall over seaside coastal regime occurs between 9 p.m. and noon.

The diurnal cycle over the Gulf of Mexico (Fig. 7c) is delayed by about three hours, when compared to that of the Pacific. Its maximum lightning activity occurs between 9 a.m. and noon, but it is still within the seaside coastal regime studied by Kikuchi and Wang (2008).

The Caribbean region (Fig. 7b) exhibits very small lightning variations throughout the day, with a slight increase near midnight. The geographical location of the region (see Fig. 2) makes it less influenced by land breeze than the Pacific regions or the Gulf of Mexico, therefore the distribution of lightning over the Caribbean Sea is quite uniform throughout the day.

\section{Summary and conclusions}

We carried out a preliminary characterization of the spatial and temporal distribution of lightning strokes to ground over Mexico and adjacent oceanic areas, using the 5-year period from 2005 to 2009. In the study, five spatial sub-regions were considered: continental Mexico, Gulf of Mexico, Caribbean, Sub-Tropical Pacific and Tropical Pacific. These sub-regions were selected to evaluate spatial and temporal distributions of lightning, since different meteorological phenomena have different relative importance for each of them.

The spatial distribution is clearly linked to the presence of mountainous regions over the continental area. The highest lightning densities are observed along the Mexican coast of Pacific covered by mountain ranges and in the states of Tabasco and Campeche, at the southern coast of the Gulf of Mexico. The Gulf of Mexico has the highest annual number of flashes per $\mathrm{km}^{2}$ because of the presence of mid-latitude systems in winter. It is followed by continental Mexico, Caribbean Sea, Tropical Pacific and Subtropical Pacific.

The maps of correlation between rainfall and lightning provide information about vertical cloud development and microphysical processes within the clouds. Maritime clouds that develop close to the coast have microphysical properties similar to continental clouds. High rainfall accompanied by high lightning activity in these clouds implies high ice amounts and strong vertical development due to the presence of continental cloud condensation nuclei (CCN). Small and numerous $\mathrm{CCN}$ of continental origin lead to a greater 
release of latent heat, stronger updrafts and longer cloud lifetime. In contrast, the clouds that develop farther to the south from the Pacific coast of Mexico exhibit negative correlation between precipitation and lightning. High rainfall production and low lightning activity in these clouds indicate small ice amounts and smaller vertical development. Larger sizes of the CCN that characterize maritime clouds imply faster growth of droplets that can initiate the process of collisioncoalescence below the $0{ }^{\circ} \mathrm{C}$ isotherm and produce warm precipitation. The lifetimes of these clouds can be insufficient for the development of the electrical field close to the breakdown point. Smaller ice concentrations imply lower efficiency of the process of charge separation which involves the interaction between different types of hydrometeors.

The seasonal cycles are calculated for every region from the WWLLN and LIS/OTD datasets. The lightning densities detected by WWLLN are about one order of magnitude lower than those registered by LIS/OTD, however both datasets exhibit very similar seasonal variation of flashes. Over the continental Mexico the highest number of flashes is observed from July to September and $91 \%$ of flashes occur during the rainy season (May to October). The Gulf of Mexico has the broadest and the most uniform seasonal distribution. The variation in flash density over Caribbean Sea is consistent with the seasonal cycle of rainfall: it decreases during midsummer drought (July and August) and is highest in October. The lightning over the Subtropical Pacific is significant only from July to October due to the convection associated with the North American Monsoon. The seasonal cycle of lightning over the Tropical Pacific does not coincide with that of rainfall: the highest number of flashes is observed during the mid-summer drought.

The diurnal cycle of lightning over continental Mexico exhibits maximum activity between 6 p.m. and 9 p.m. This relatively late peak reflects the high contribution from flashes over coastal areas to the total number of flashes over the continent. For the Subtropical and Tropical Pacific, the highest number of flashes is observed between midnight and 9 a.m.; the lightning activity follows the land-sea breeze cycle. The diurnal cycle over the Gulf of Mexico is delayed by about three hours when compared to that of the Pacific and the Caribbean Sea has the most uniform diurnal distribution of lightning due to the smallest influence of land breeze. The above results are consistent with the diurnal precipitation regimes identified by Kikuchi and Wang (2008).

The results presented in this study are in general consistent with the current knowledge on the spatial and temporal variability of lightning and rainfall; however there are some open issues which need further investigation. High lightning density in January over the region: $110^{\circ} \mathrm{W}-120^{\circ} \mathrm{W}, 10^{\circ} \mathrm{N}-$ $15^{\circ} \mathrm{N}$, and the discrepancy between the seasonal cycle of rainfall and that of lightning over the Tropical Pacific are the examples of "the unsolved problems" that have been highlighted by this climatological study. The authors of these paper plan to analyse additional TRMM data registered by passive and active sensors in order to offer possible explanations.

Acknowledgements. The authors wish to acknowledge the World Wide Lightning Location Network (http://wwlln.net), a consortium of over 40 universities and research institutions, from which the lightning location data used in this paper is obtained. We gratefully acknowledge R. Holzworth and his team at the University of Washington, for careful data monitoring and constant improvement of the retrieval algorithm. This study was partially funded by Consejo Nacional de Ciencia de Tecnología de México (through grants SEP-Conacyt 62071 and SEMARNAT-Conacyt 23499).

Topical Editor P. Drobinski thanks two anonymous referees for their help in evaluating this paper, and the authors are grateful for their useful comments.

\section{References}

Abarca, S. F., Corbosiero, K. L., and Galarneau Jr., T. J.: An evaluation of the Worldwide Lightning Location Network (WWLLN) using the National Lightning Detection Network (NLDN) as ground truth, J. Geophys. Res., 115, D18206, doi:10.1029/2009JD013411, 2010.

Avila, E. E., Pereyra, R. G., Aguirre Varela, G. G., and Caranti, G. M.: The effect of the cloud-droplet spectrum on electrical-charge transfer during individual ice-ice collisions, Q. J. Roy. Meteorol. Soc., 125(557), 1669-1679, 1999.

Baumgardner, D., Raga, G. B., Grutter, M., and Lammel, G.: Evolution of anthropogenic aerosols in the coastal town of Salina Cruz, Mexico: Part I particle dynamics and land-sea interactions, Sci. Tot. Env., 367, 288-301, 2006.

Boccippio, D. J., Cummins, K. L, Christian, H. J., and Goodman, S. J.: Combined satellite and surface-based estimation of the intracloud-cloud-to-ground lightning ratio over the continental United States, Mon. Weather Rev., 129, 108-122, 2001.

Cecil, D. J., Goodman, S. J., Boccippio, D. J., Zipser, E. J., and Nesbitt, S. W.: Three Years of TRMM Precipitation Features. Part I: Radar, Radiometric, and Lightning Characteristics, Mon. Weather Rev., 133, 543-566, 2005.

Christian, H. J., Blakeslee, R. J., Boccippio, D. J., Boeck, W. L., Buechler D. E., Driscoll, K. T., Goodman, S. J., Hall, J. M., Koshak, W. J., Mach, D. M., and Stewart, M. F.: Global frequency and distribution of lightning as observed from space by the Optical Transient Detector, J. Geophys. Res., 108(D1), 4005, doi:10.1029/2002JD002347, 2003.

Dirección General de Información en Salud (DGIS): Base de datos de defunciones 1979-2007. Sistema Nacional de Información en Salud (SINAIS). [México]: Secretaría de Salud, http://www. sinais.salud.gob.mx, last access: 1 May 2010.

Dowden, R. L., Brundell, J. B., and Rodger, C. J.: VLF lightning location by time of group arrival (TOGA) at multiples sites, J. Atmos. Solar Terr. Phys., 64, 817-830, 2002.

Gamble, D. W., Parnell, D. B., and Curtis, S.: Spatial variability of the Caribbean midsummer drought and relation to the North Atlantic High, Int. J. Climatol., 28, 343-350, 2008.

Hudson, J. G. and Yum, S. S.: Maritime-Continental Drizzle Contrasts in Small Cumuli, J. Atmos. Sci., 58, 915-926, 2001.

Jacobson, A. R., Holzworth, R., Harlin, J., Dowden, R., and Lay, E.: Performance Assessment of the World Wide Lightning Lo- 
cation Network (WWLLN), Using the Los Alamos Sferic Array (LASA) as Ground Truth, J. Atmos Ocean. Tech., 23, 1082$1092,2006$.

Jáuregui, E.: Climatology of landfalling hurricanes and tropical storms in Mexico, Atmósfera, 16, 193-204, 2003.

Kikuchi, K. and Wang, B.: Diurnal precipitation regimes in global tropics, J. Climate, 21, 2680-2696, 2008.

Kucieńska, B., Montero-Martínez, G., and García-García, F.: A simulation of the influence of organic and inorganic pollutants on the formation and development of warm clouds over Mexico City, Atmos. Res., 95, 487-495, 2010.

Kucieńska, B. and Raga, G.: Climatology of precipitation and lightning over the Pacific coast of southern Mexico retrieved from Tropical Rainfall Measuring Mission satellite products and World Wide Lightning Location Network data, Int. J. Remote Sens., in review, 2010.

Kummerow, C. and Barnes, W.: The Tropical Rainfall Measuring Mission (TRMM) sensor package, J. Atmos. Oceanic Technol., 15, 809-816, 1998.

Kummerow, C., Simpson, J., Thiele, O., Barnes, W., Chang, A. T. C., Stocker, E., Adler, R. F., Hou, A., Kakar, R., Wentz, F., Ashcroft, P., Kozu, T., Hong, Y., Okamoto, K., Iguchi, T., Kuroiwa, H., Im, E., Haddad, Z., Huffman, G., Ferrier, B., Olson, W. S., Zipser, E., Smith, E. A., Wilheit, T. T., North, G., Krishnamurti, T., and Nakamura, K.: The status of the Tropical Rainfall Measuring Mission (TRMM) after two years in orbit, J. Appl. Meteorol., 39, 1965-1982, 2000.

Lay, E. H., Holzworth, R. H., Rodger, C. J., Thomas, J. N., Pinto, O., and Dowden, R. L.: WWLL Global Lightning Detection System: Regional Validation Study in Brazil, Geophys. Res. Lett., 31, L03102, doi:10.1029/2003GL018882, 2004.

Lay, E. H., Jacobson, A. R., Holzworth, R. H., Rodger, C. J., and Dowden, R. L.: Local time variation in land/ocean lightning flash density as measured by the World Wide Lightning Location Network, J. Geophys Res., 112, D13111, doi:10.1029/2006JD007944, 2007.

Mackerras, D., Darveniza, M., Orville, R. E., Williams, E. R., and Goodman, S. J.: Global lightning: Total, cloud and ground flash estimates, J. Geophys. Res., 103, 19791-19809, 1998.

Magaña, V., Amador J. A., and Medina, S.: The midsummer drought over Mexico and Central America, J. Climate, 12, 1577$1588,1999$.
Montero-Martínez, G., Zarraluqui-Such, V., Caetano, E. S., and García-García, F.: Hydrometeor vertical characterization of precipitating clouds over the Mexico Basin, Int. J. Remote Sens., in press, doi:10.1080/01431161.2010.510489, 2010.

Petersen, W. A., Christian, H. J., and Rutledge, S. A.: TRMM observations of the global relationship between ice water content and lightning, Geophys. Res. Lett., 32, L14819, doi:10.1029/2005GL023236, 2005.

Ramachandran, V., Prakash, J. N., Deo, A., and Kumar, S.: Lightning stroke distance estimation from single station observation and validation with WWLLN data, Ann. Geophys., 25, 15091517, doi:10.5194/angeo-25-1509-2007, 2007.

Rodger, C. J., Brundell, J. B., Dowden, R. L., and Thomson, N. R.: Location accuracy of long distance VLF lightning locationnetwork, Ann. Geophys., 22, 747-758, doi:10.5194/angeo-22-7472004, 2004.

Rodger, C. J., Brundell, J. B., and Dowden, R. L.: Location accuracy of VLF World-Wide Lightning Location (WWLL) network: Post-algorithm upgrade, Ann. Geophys., 23, 277-290, doi:10.5194/angeo-23-277-2005, 2005.

Romero-Centeno, R., Zavala-Hidalgo, J., and Raga, G. B.: Midsummer gap winds and low-level circulation over the eastern tropical Pacific, J. Climate, 20, 3768-84, 2007.

Saunders C.: Charge separation mechanisms in clouds, Space Sci. Rev., 137, 335-353, 2008.

Stolzenburg, M. and Marshall, T. C.: Electric Field and Charge Structure in Lightning-Producing Clouds (book chapter). Lightning: Principles, Instruments and Applications, Springer, pp. 5782, 2009.

Takayabu, Y. N.: Rain-yield per flash calculated from TRMM PR and LIS data and its relationship to the contribution of tall convective rain, Geophys. Res. Lett., 33, L18705, doi:10.1029/2006GL027531, 2006.

Tapia, A., Smith, J. A., and Dixon, M.: Estimation of Convective Rainfall from Lightning Observations, J. Appl. Meteor., 37, 1497-1509, 1998.

Twomey, S. and Wojciechowski, T. A.: Observations of the geographical variations of cloud nuclei, J. Atmos. Sci., 26, 684-688, 1969. 